\title{
Inequalities in the prevalence of undiagnosed hypertension among Bangladeshi adults: evidence from a nationwide survey
}

Sayem Ahmed ${ }^{1,2,3^{*}}$ (D, Md. Tariqujjaman ${ }^{1}$, Md. Arafat Rahman ${ }^{4}$, Md. Zahid Hasan ${ }^{1}$ and Md. Mehedi Hasan ${ }^{5}$

\begin{abstract}
Background: In recent years, developing countries like Bangladesh are facing a higher burden of non-communicable diseases such as hypertension as a result of demographic transition. Prevalence of hypertension is often studied in this setting. However, evidence on undiagnosed hypertension is not widely available in the existing literature. Therefore, the current study focuses on inequalities in the prevalence of undiagnosed hypertension in Bangladesh.

Methods: A total of 8835 participants aged 35+ years were included in this study using nationally representative Bangladesh Demographic and Health Survey 2011 (BDHS). In the survey, systolic blood pressure (SBP) and diastolic blood pressure (DBP) of these participants were measured three times with approximately 10 minutes of an interval between each measurement. Any respondent with either SBP $\geq 140 \mathrm{mmHg}$ or DBP $\geq 90 \mathrm{mmHg}$ was considered as patient with hypertension as per the guidelines from American Heart Association. Among the participants, undiagnosed hypertension was defined as having SBP $>=140 \mathrm{mmHg}$ or DBP $>=90 \mathrm{mmHg}$ and never taking prescribed medicine or being told by health professionals to lower/control blood pressure. Multiple logistic regression analysis was applied for identifying factors associated with undiagnosed hypertension. Further, socioeconomic inequalities in the prevalence of undiagnosed hypertension were estimated using Concentration Index (C).
\end{abstract}

Results: We found 978 (59.9\% of the total) were undiagnosed among 1685 hypertensive patients studied. Regression analysis showed individuals with being underweight, having poor socioeconomic conditions, and lower educational qualifications were more likely to have undiagnosed hypertension. A similar association between undiagnosed hypertension and socioeconomic quintiles was observed using concentration index ( $C=-0.07)$. On the other hand, individuals from higher age group (50-64 or above), female sex, and Sylhet region were at lower risk of undiagnosed hypertension.

Conclusions: This study showed that a large proportion of the cases with hypertension are remained undiagnosed in Bangladesh, especially among the poor and low educated population. Screening and awareness building initiatives on hypertension should be taken for this group of population to reduce the burden of undiagnosed hypertension.

Keywords: Undiagnosed hypertension, Non-communicable disease, Concentration index, Bangladesh

\footnotetext{
* Correspondence: sayemahmed@icddrb.org

${ }^{1}$ International Centre for Diarrhoeal Disease Research, Bangladesh (icddr,b),

Dhaka 1212, Bangladesh

${ }^{2}$ Department of Learning, Informatics, Management and Ethics, Karolinska

Institutet, Stockholm 171 77, Sweden

Full list of author information is available at the end of the article
}

(c) The Author(s). 2019 Open Access This article is distributed under the terms of the Creative Commons Attribution 4.0 International License (http://creativecommons.org/licenses/by/4.0/), which permits unrestricted use, distribution, and reproduction in any medium, provided you give appropriate credit to the original author(s) and the source, provide a link to the Creative Commons license, and indicate if changes were made. The Creative Commons Public Domain Dedication waiver (http://creativecommons.org/publicdomain/zero/1.0/) applies to the data made available in this article, unless otherwise stated. 


\section{Introduction}

Hypertension is a leading risk factor for cardiovascular diseases, stroke, kidney failure, disability, and premature death [1,2]. Globally, in 2008, about 40\% (aged 25 years or above) had been diagnosed with hypertension and currently, over one billion people are living with this condition [3]. In the Asian region, hypertension has become a major public health challenge, affecting more than $35 \%$ of the adult population [4]. Due to demographic transition, the number of elderly people is increasing in low-and-middle-income countries (LMICs) which is leading to a higher prevalence of non-communicable diseases (NCDs) like hypertension in this region $[5,6]$. It was estimated that more than $13 \%$ of the total deaths around the world were related to hypertension in 2010. Such hypertension related mortality is rising rapidly in LMICs [7]. In the South-East Asian region, hypertension affects one in three adults and the trend of hypertension is increasing [8]. The prevalence of hypertension among all adults and elderly people (age $\geq 60$ years) in Bangladesh is 25 and $40 \%$ respectively [9].

In LMICs, like Bangladesh, hypertension disproportionately affects many people and is often undiagnosed compared to high-income countries [3]. For prevention, treatment, and control of hypertension, it is crucial to diagnose this condition. Moreover, this undiagnosed hypertensive condition may lead to serious health complications or even deaths.

The Government of Bangladesh is constitutionally committed to providing minimum healthcare to every citizen that includes health services, health education, health promotion, and rehabilitation. The health systems of this country have 3 tiers structure including primary (e.g. Community Clinic, Upazila Health Complex), secondary (e.g. District Hospital), and tertiary level (e.g. Medical College Hospital, Specialized Facilities) healthcare facilities covering all villages, subdistricts, and districts. The secondary and tertiary level of healthcare facilities are currently delivering treatment for hypertension and the government has planned to extend this service up to primary level [10]. Beside the public facilities, there are a number of private and non-profit NGO clinics, hospitals, and diagnostic centres across the country providing healthcare services.

Several studies estimated the prevalence of hypertension in Bangladesh $[5,11,12]$. However, the evidence on the national prevalence of undiagnosed hypertension is still limited. Islam et al. 2016 and Khanam et al. 2012 estimated prevalence of undiagnosed hypertension in rural settings using a small sample size [9, 13]. Islam et al. 2016 found that $82 \%$ among the hypertensive patients were undiagnosed in a rural district [13] and Khanam et al. 2012 showed that $11.1 \%$ of the total population were undiagnosed for hypertension from the Matlab rural surveillance sites of Bangladesh [9]. The national level estimate of undiagnosed hypertension prevalence is essential for planning effective strategies to reduce the burden of hypertension. Therefore, we aimed to estimate the prevalence of undiagnosed hypertension and its socioeconomic inequalities in Bangladesh.

\section{Methods}

\section{Design and settings}

For this study, we used secondary data derived from the Bangladesh Demographic and Health Survey (BDHS) 2011. BDHS employed two-stage stratified sampling procedure to collect the data. In the first stage, BDHS selected 600 (207 in urban and 393 in rural) enumeration areas with probability proportional to size. In the second stage, on average a systematic sample of 30 households was selected per enumeration areas.

\section{Participants}

In total 17,141 households consisting 83,731 individuals were surveyed. We included 8835 adult participants of both sexes aged $35+$ years in this study since this group is at higher risk of hypertension [14]. We found 1685 cases with hypertension; systolic blood pressure $(\mathrm{SBP})>=140$ $\mathrm{mmHg}$ or diastolic blood pressure (DBP) $>=90 \mathrm{mmHg}$. A detail of sample selection is presented in Fig. 1.

\section{Outcome variable}

In BDHS 2011, the blood pressure level of participants was recorded and used for measuring hypertension. To measure blood pressure level "LIFE SOURCE UA-767 Plus Blood Pressure Monitor" device was used as recommended by World Health Organization (WHO). Well-trained health technicians were employed to measure and record the blood pressure of the participants. As the blood pressure levels vary within a short period of time, BDHS measured SBP and DBP three times with approximately 10 minutes of an interval between each measurement. Finally, the average of the last two measurements was considered to detect hypertension among the participants. Hypertension was defined using the guidelines from the American Heart Association (AHA) [14]. According to the AHA, a participant with $\mathrm{SBP}>=140 \mathrm{mmHg}$ or $\mathrm{DBP}>=90 \mathrm{mmHg}$ is diagnosed as a hypertension case. Among these cases with hypertension, undiagnosed hypertension was defined as having $\mathrm{SBP}>=140 \mathrm{mmHg}$ or $\mathrm{DBP}>=90 \mathrm{mmHg}$ and never taking prescribed medicine or being told by health professionals to lower/control blood pressure [15].

\section{Explanatory variables}

The socioeconomic status of each household was measured by asset index constructed using principal 


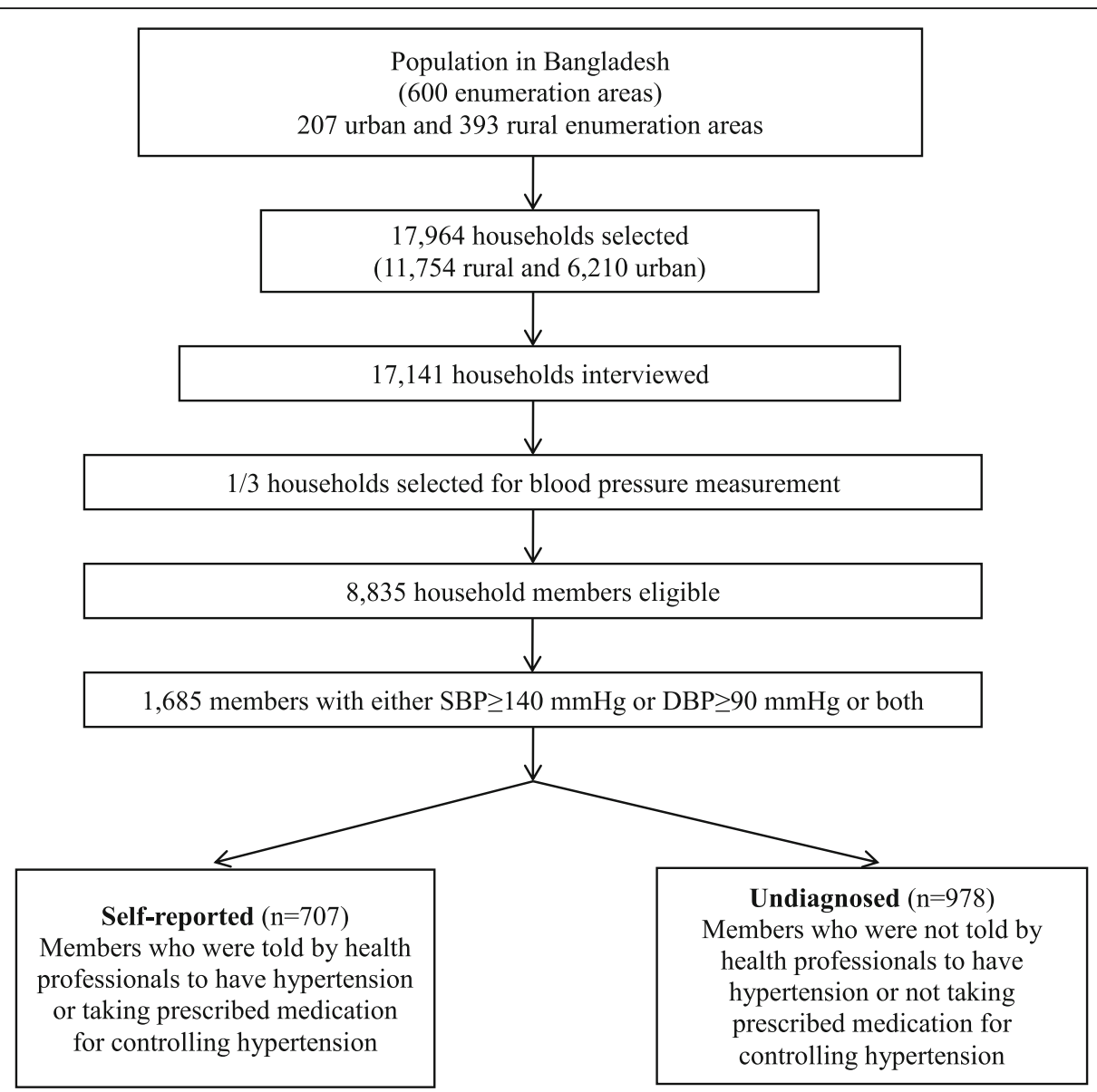

Fig. 1 Sample selection flow chart. SBP = Systolic Blood Pressure, DBP = Diastolic Blood Pressure

component analysis (PCA) approach. The PCA is a widely used technique for computing asset indices based on the ownership of durable assets in the households and infrastructure and housing characteristics (e.g. source of water, sanitation facility, housing structure) [16]. Traditionally the technique was applied to continuous variables, however, Filmer and Pritchett (2001) argued that PCA can be a valid method for categorical and binary data like ownership of assets [17]. Higher scores of the index indicate more affluent households. All the households were ranked from the lowest to the highest asset score and divided into 5 quintiles. Confounders included in this study were age group (35-49 years, 50-64 years, and 65+ years), sex (Male and Female), educational status (No institutional education, Primary, Secondary, and Higher), marital status (Currently married, Divorced/widowed/separated), nutritional status (Underweight: body-mass index $(\mathrm{BMI})<18.5$ $\mathrm{kg} / \mathrm{m}^{2}$, Normal: BMI $>=18.5 \mathrm{~kg} / \mathrm{m}^{2}$ and BMI $<25 \mathrm{~kg} / \mathrm{m}^{2}$, and Overweight/Obese: BMI $>=25 \mathrm{~kg} / \mathrm{m}^{2}$ ), households with children (dummy: $0=$ No child and $1=$ has child), administrative division (Barisal, Chittagong, Dhaka, Khulna,
Rajshahi, Rangpur, and Sylhet), and place of residence (Urban and Rural).

\section{Statistical analyses}

Univariate analysis for calculating percentages of categorical variables was applied to describe the characteristics of the sampled population. Bivariate analysis using Chi-square test was employed to investigate the differentials in the prevalence of undiagnosed hypertension over background characteristics. All the analyses were done taking into account the complex survey design for capturing variations due to weighting and designing of the survey.

Multiple logistic regression models were applied to explore the potential determinants of undiagnosed hypertension. In multiple logistic regression models, we included only the variables those were found significantly associated with undiagnosed hypertension in the simple logistic regression models. The results of simple and multiple logistic regression analyses were presented in terms of unadjusted odds ratios (OR) and adjusted odds ratios (AOR) along with their respective $95 \%$ confidence intervals (CIs). 
Three separate multiple logistic regression models were fitted at three levels of background characteristics namely, individual level (model 2), household level (model 3), and finally community level (model 4).

The concentration index $(\mathrm{C})$, along with standard error (SE) of C, was estimated to show the direction of undiagnosed hypertension prevalence across different socioeconomic groups of households. In calculating $\mathrm{C}$, we ranked the households according to their socioeconomic characteristics from the poorest to the richest. Distribution of undiagnosed hypertension was measured by plotting a concentration curve representing the cumulative proportion of undiagnosed hypertension in Y-axis and cumulative proportions of the population in $\mathrm{X}$-axis. If the prevalence of undiagnosed hypertension is equally distributed across socioeconomic groups, the concentration curve will coincide with the diagonal. In contrast, if there are inequalities in the prevalence of undiagnosed hypertension, the concentration curve will deviate from the diagonal. The $\mathrm{C}$ is defined as twice the area between the concentration curve and the diagonal [18-20]. The index value can range between -1 and +1 , a positive value implies prevalence of undiagnosed hypertension is more concentrated among the better-off socioeconomic group and a negative value implies prevalence is more concentrated among less affluent group [19, 21]. STATA (version 13) was used to perform all the analyses [22].

\section{Results}

\section{Characteristics of the study participants}

The background characteristics of the study participants are presented in Table 1. Among the patients studied, more than one-third (37.8\%) were between 35 and 49 years of age and $61.7 \%$ were female. Around half (51.0\%) of the patients had no institutional education whereas only $9.0 \%$ had higher education. However, almost two out of every three patients were currently married (73.8\%). Around $57.3 \%$ of the patients had normal BMI and $71.3 \%$ lived in rural area.

\section{Prevalence of undiagnosed hypertension}

Among 1685 hypertensive patients (SBP $>=140$ or DBP > $=90)$ studied, 978 cases with hypertension (59.9\% of total) were found to be undiagnosed. About $65.9 \%$ of these undiagnosed patients were aged between 35 and 49 years. The prevalence of undiagnosed hypertension was higher among male patients (66.9\%) compared to female $(55.5 \%)$ and it was lower among the higher education group (49.4\%) compared to no education group (63.9\%). Moreover, the rate of undiagnosed hypertension was found to be higher among the underweight people (65.5\%). In terms of wealth index, the prevalence of undiagnosed hypertension was higher among the people from the poorest (69.7\%) and poorer $(69.6 \%)$ quintiles compared to people belonged to the richest (50.8\%) quintile. Significant variations in the prevalence of undiagnosed hypertension were observed among people from seven administrative divisions (Chi-square value $=22.1, p$-value $<0.01)($ Table 2$)$.

\section{Determinants of undiagnosed hypertension}

In the unadjusted logistic regression model, we found that patient's age, education, BMI, administrative division, place of residence, and wealth status were significantly associated with undiagnosed hypertension. Results from multiple logistic regression models, adjusted for individual characteristics (model 2) and that of household characteristics, (model 3) were similar to the unadjusted model. The logistic regression model was adjusted by all the significant variables (significantly associated with undiagnosed hypertension) in the unadjusted model.

In model 4 , old aged patients (age 50 years or more) were less likely to have undiagnosed hypertension compared to the younger aged (age 35-49 years) patients $(\mathrm{AOR}=0.53 ; 95 \% \mathrm{CI}=0.41-0.68$ for $50-64$ years and $\mathrm{AOR}=0.49 ; 95 \% \mathrm{CI}=0.36-0.66$ for $65+$ years). Patients who received secondary and higher education were $30 \%$ $(\mathrm{AOR}=0.70 ; 95 \% \mathrm{CI}=0.5-0.98)$ and $57 \%(\mathrm{AOR}=0.43$; 95\% CI $=0.27-0.68$ ) less likely to have undiagnosed hypertension respectively as compared to the patients with no education. The likelihood of having undiagnosed hypertension were less among female patients $(\mathrm{AOR}=0.68 ; 95 \% \mathrm{CI}=0.48-0.97)$ and overweight $/$ obese patients (AOR $=0.65 ; 95 \% \mathrm{CI}=0.5-0.85)$ compared to male and patients with normal body weight respectively. Patients from the poorest and poorer asset quintiles were $1.86(\mathrm{AOR}=1.86 ; 95 \% \mathrm{CI}=1.25-2.78)$ and $1.78(\mathrm{AOR}=1.78 ; 95 \% \mathrm{CI}=1.16-2.72)$ times more likely to have undiagnosed hypertension than the patients from the richest wealth quintile. Compared to the Khulna division, people living in Sylhet division were $45 \%$ less likely to have undiagnosed hypertension $(\mathrm{AOR}=0.55 ; 95 \% \mathrm{CI}=0.37-0.84)$ (Table 3$)$.

\section{Socioeconomic inequalities in undiagnosed hypertension}

Socioeconomic inequalities in the prevalence of undiagnosed hypertension are presented in Table 4. Findings showed that the prevalence of undiagnosed hypertension was distributed among poor socioeconomic groups $(C=-0.07$; SE of $C=0.01)$. The absolute measure of inequality depicted that the prevalence of undiagnosed hypertension was greater by $18.9 \%(\mathrm{Q} 1-\mathrm{Q} 5=18.9 \%)$ among the poorest group than the richest group. Similarly, from the distribution of the prevalence of undiagnosed hypertension, we found poor (Q1) vs rich (Q5) ratio as 1.37 in Bangladesh. The disparities in undiagnosed hypertension was higher in Sylhet division $(C=-0.17$, SE 
Table 1 Characteristics of study population

\begin{tabular}{|c|c|c|c|c|}
\hline \multirow[t]{2}{*}{ Characteristics } & \multirow[t]{2}{*}{$\begin{array}{l}\text { Frequency } \\
(N=1685)\end{array}$} & \multirow[t]{2}{*}{$\begin{array}{l}\text { Percentage } \\
(\%)\end{array}$} & \multicolumn{2}{|c|}{$\begin{array}{l}95 \% \text { Confidence } \\
\text { interval }\end{array}$} \\
\hline & & & $\begin{array}{l}\text { Lower } \\
\text { bound (\%) }\end{array}$ & $\begin{array}{l}\text { Upper } \\
\text { bound (\%) }\end{array}$ \\
\hline \multicolumn{5}{|l|}{ Individual characteristics } \\
\hline \multicolumn{5}{|l|}{ Age in years } \\
\hline $35-49$ & 635 & 37.8 & 35.4 & 40.3 \\
\hline $50-64$ & 575 & 33.8 & 31.3 & 36.3 \\
\hline$>=65$ & 475 & 28.4 & 25.8 & 31.0 \\
\hline \multicolumn{5}{|l|}{ Sex } \\
\hline Male & 663 & 38.3 & 35.8 & 40.7 \\
\hline Female & 1022 & 61.7 & 59.3 & 64.2 \\
\hline \multicolumn{5}{|l|}{ Education } \\
\hline No education & 804 & 51.0 & 48.1 & 53.9 \\
\hline Primary & 411 & 23.5 & 21.0 & 25.9 \\
\hline Secondary & 305 & 16.5 & 14.6 & 18.5 \\
\hline Higher & 165 & 9.0 & 7.3 & 10.7 \\
\hline \multicolumn{5}{|l|}{ Marital status } \\
\hline Currently married & 1244 & 73.8 & 71.4 & 76.1 \\
\hline Divorced/separated/others & 441 & 26.2 & 23.9 & 28.6 \\
\hline \multicolumn{5}{|l|}{ Body weight } \\
\hline Normal & 899 & 57.3 & 54.7 & 59.9 \\
\hline Underweight & 341 & 21.7 & 19.3 & 24.0 \\
\hline Overweight/obese & 366 & 21.0 & 18.8 & 23.2 \\
\hline \multicolumn{5}{|l|}{ Household characteristics } \\
\hline \multicolumn{5}{|l|}{ HH having child } \\
\hline No child & 1070 & 64.1 & 61.3 & 66.9 \\
\hline Has child & 615 & 35.9 & 33.1 & 38.7 \\
\hline \multicolumn{5}{|l|}{ Wealth index } \\
\hline Poorest & 232 & 15.2 & 12.9 & 18.0 \\
\hline Poorer & 257 & 16.6 & 14.3 & 18.9 \\
\hline Middle & 286 & 17.4 & 15.1 & 19.7 \\
\hline Richer & 375 & 22.0 & 19.5 & 24.6 \\
\hline Richest & 535 & 28.7 & 25.7 & 31.8 \\
\hline \multicolumn{5}{|l|}{ Community characteristics } \\
\hline \multicolumn{5}{|l|}{ Division } \\
\hline Barisal & 180 & 5.6 & 4.8 & 6.5 \\
\hline Chittagong & 192 & 12.5 & 10.8 & 14.2 \\
\hline Dhaka & 304 & 34.0 & 31.1 & 36.9 \\
\hline Khulna & 327 & 16.7 & 14.4 & 19.0 \\
\hline Rajshahi & 225 & 12.5 & 10.8 & 14.2 \\
\hline Rangpur & 302 & 14.5 & 12.8 & 16.2 \\
\hline Sylhet & 155 & 4.1 & 3.3 & 4.9 \\
\hline \multicolumn{5}{|l|}{ Place of residence } \\
\hline Urban & 649 & 28.7 & 26.2 & 31.2 \\
\hline Rural & 1036 & 71.3 & 68.8 & 73.8 \\
\hline
\end{tabular}


Table 2 Prevalence of undiagnosed hypertension among patients aged 35 years or above by background characteristics

\begin{tabular}{|c|c|c|c|c|}
\hline \multirow[t]{2}{*}{ Characteristics } & \multirow{2}{*}{$\begin{array}{l}\text { Undiagnosed } \\
\text { Hypertension (\%) }\end{array}$} & \multicolumn{2}{|c|}{ 95\% Confidence interval } & \multirow{2}{*}{$\begin{array}{l}\text { Chi-square value } \\
\text { ( } p \text {-value) }\end{array}$} \\
\hline & & Lower bound (\%) & Upper bound (\%) & \\
\hline \multicolumn{5}{|l|}{ Individual characteristics } \\
\hline \multicolumn{4}{|l|}{ Age in years } & \multirow{4}{*}{$\begin{array}{l}15.2 \\
(0.002)\end{array}$} \\
\hline $35-49$ & 65.9 & 61.9 & 69.7 & \\
\hline $50-64$ & 56.1 & 51.0 & 61.0 & \\
\hline$>=65$ & 56.5 & 51.4 & 61.5 & \\
\hline \multicolumn{4}{|l|}{ Sex } & \multirow{3}{*}{$\begin{array}{l}21.5 \\
(<0.001)\end{array}$} \\
\hline Male & 66.9 & 62.8 & 70.8 & \\
\hline Female & 55.5 & 51.8 & 59.2 & \\
\hline \multicolumn{4}{|l|}{ Education } & \multirow{5}{*}{$\begin{array}{l}14.8 \\
(0.007)\end{array}$} \\
\hline No education & 63.9 & 59.9 & 67.7 & \\
\hline Primary & 57.5 & 51.9 & 62.9 & \\
\hline Secondary & 56.7 & 50.4 & 62.8 & \\
\hline Higher & 49.4 & 41.4 & 57.4 & \\
\hline \multicolumn{4}{|l|}{ Marital status } & \multirow{3}{*}{$\begin{array}{l}3.9 \\
(0.085)\end{array}$} \\
\hline Currently married & 61.3 & 58.2 & 64.3 & \\
\hline Divorced/separated/others & 56.0 & 50.3 & 61.4 & \\
\hline \multicolumn{4}{|l|}{ Body weight } & \multirow{4}{*}{$\begin{array}{l}31.9 \\
(<0.001)\end{array}$} \\
\hline Normal & 62.6 & 59.0 & 66.1 & \\
\hline Underweight & 65.5 & 59.1 & 71.4 & \\
\hline Overweight/obese & 46.7 & 40.6 & 52.9 & \\
\hline \multicolumn{5}{|l|}{ Household characteristics } \\
\hline \multicolumn{4}{|l|}{ HH having child } & \multirow{3}{*}{$\begin{array}{l}0.0 \\
(0.861)\end{array}$} \\
\hline No child & 59.7 & 56.2 & 63.1 & \\
\hline Has child & 60.2 & 55.7 & 64.5 & \\
\hline \multicolumn{4}{|l|}{ Wealth index } & \multirow{6}{*}{$\begin{array}{l}40.5 \\
(<0.001)\end{array}$} \\
\hline Poorest & 69.7 & 63.0 & 75.7 & \\
\hline Poorer & 69.6 & 62.4 & 76.0 & \\
\hline Middle & 61.8 & 55.5 & 67.7 & \\
\hline Richer & 56.1 & 50.3 & 61.7 & \\
\hline Richest & 50.8 & 45.9 & 55.8 & \\
\hline \multicolumn{5}{|l|}{ Community characteristics } \\
\hline \multicolumn{4}{|l|}{ Division } & \multirow{8}{*}{$\begin{array}{l}22.1 \\
(0.004)\end{array}$} \\
\hline Khulna & 61.6 & 55.6 & 67.4 & \\
\hline Barisal & 55.9 & 47.8 & 63.7 & \\
\hline Chittagong & 52.9 & 45.6 & 60.1 & \\
\hline Dhaka & 59.7 & 53.8 & 65.2 & \\
\hline Rajshahi & 58.7 & 51.6 & 65.5 & \\
\hline Rangpur & 70.7 & 64.3 & 76.4 & \\
\hline Sylhet & 47.0 & 36.3 & 58.0 & \\
\hline \multicolumn{4}{|l|}{ Place of residence } & 4.5 \\
\hline Urban & 55.9 & 50.8 & 60.8 & \\
\hline Rural & 61.5 & 58.2 & 64.8 & \\
\hline Total & 59.9 & 57.1 & 62.6 & - \\
\hline
\end{tabular}


Table 3 Risk factors associated with undiagnosed hypertension among patients aged 35 years or more in Bangladesh

\begin{tabular}{|c|c|c|c|c|}
\hline \multirow[t]{2}{*}{ Characteristics } & \multicolumn{4}{|c|}{ Odds Ratio (95\% Confidence interval) } \\
\hline & Model 1 (univariate) ${ }^{1}$ & Model $2^{2}$ & Model $3^{3}$ & Model $4^{4}$ \\
\hline \multicolumn{5}{|l|}{ Individual characteristics } \\
\hline \multicolumn{5}{|l|}{ Age in years } \\
\hline $35-49$ & 1.00 & 1.00 & 1.00 & 1.00 \\
\hline $50-64$ & $0.66^{* * *}(0.53-0.84)$ & $0.51^{* * *}(0.4-0.66)$ & $0.52^{* * *}(0.41-0.68)$ & $0.53^{* * *}(0.41-0.68)$ \\
\hline$>=65$ & $0.69^{* * *}(0.54-0.88)$ & $0.46^{* * *}(0.34-0.61)$ & $0.47^{* * *}(0.35-0.64)$ & $0.49^{* * *}(0.36-0.66)$ \\
\hline \multicolumn{5}{|l|}{ Sex } \\
\hline Male & 1.00 & 1.00 & 1.00 & 1.00 \\
\hline Female & $0.65^{* * *}(0.53-0.8)$ & $0.68^{* *}(0.48-0.96)$ & $0.68^{* *}(0.48-0.97)$ & $0.68^{* *}(0.48-0.97)$ \\
\hline \multicolumn{5}{|l|}{ Education } \\
\hline No education & 1.00 & 1.00 & 1.00 & 1.00 \\
\hline Primary & $0.81 *(0.63-1.03)$ & $0.71^{* *}(0.54-0.93)$ & $0.79 *(0.6-1.04)$ & $0.81(0.61-1.07)$ \\
\hline Secondary & $0.76^{* *}(0.58-0.99)$ & $0.56^{* * *}(0.41-0.76)$ & $0.70^{* *}(0.5-0.97)$ & $0.70^{* *}(0.5-0.98)$ \\
\hline Higher & $0.52^{* * *}(0.37-0.73)$ & $0.34^{* * *}(0.22-0.52)$ & $0.44^{* * *}(0.28-0.69)$ & $0.43^{* * *}(0.27-0.68)$ \\
\hline \multicolumn{5}{|l|}{ Marital status } \\
\hline Currently married & 1.00 & - & - & - \\
\hline Divorced/separated/others & $0.83^{*}(0.67-1.03)$ & - & - & - \\
\hline \multicolumn{5}{|l|}{ Body mass index } \\
\hline Normal & 1.00 & 1.00 & 1.00 & 1.00 \\
\hline Underweight & $1.23(0.95-1.59)$ & $1.35^{* *}(1.03-1.78)$ & $1.25(0.94-1.65)$ & $1.28^{*}(0.96-1.7)$ \\
\hline Overweight/obese & $0.55^{* * *}(0.43-0.71)$ & $0.60^{* * *}(0.46-0.78)$ & $0.65^{* * *}(0.49-0.84)$ & $0.65^{* * *}(0.5-0.85)$ \\
\hline \multicolumn{5}{|l|}{ Household characteristics } \\
\hline \multicolumn{5}{|l|}{$\mathrm{HH}$ having child } \\
\hline No child & 1.00 & - & - & - \\
\hline Has child & $0.92(0.75-1.12)$ & - & - & - \\
\hline \multicolumn{5}{|l|}{ Wealth index } \\
\hline Richest & 1.00 & - & 1.00 & 1.00 \\
\hline Richer & $1.33^{* *}(1.02-1.74)$ & - & $1.15(0.86-1.54)$ & $1.11(0.82-1.5)$ \\
\hline Middle & $1.59^{* * *}(1.19-2.12)$ & - & $1.28(0.92-1.79)$ & $1.25(0.87-1.8)$ \\
\hline Poorer & $2.53^{* * *}(1.84-3.47)$ & - & $1.90^{* * *}(1.32-2.74)$ & $1.86^{* * *}(1.25-2.78)$ \\
\hline Poorest & $2.61^{* * *}(1.88-3.63)$ & - & $1.83^{* * *}(1.23-2.72)$ & $1.78^{* * *}(1.16-2.72)$ \\
\hline \multicolumn{5}{|l|}{ Community characteristics } \\
\hline \multicolumn{5}{|l|}{ Division } \\
\hline Khulna & 1.00 & - & - & 1.00 \\
\hline Barisal & $0.82(0.57-1.18)$ & - & - & $0.8(0.53-1.19)$ \\
\hline Chittagong & $0.71 *(0.5-1.02)$ & - & - & $0.88(0.6-1.3)$ \\
\hline Dhaka & $0.97(0.71-1.33)$ & - & - & $1.03(0.73-1.45)$ \\
\hline Rajshahi & $0.93(0.66-1.32)$ & - & - & $0.97(0.67-1.41)$ \\
\hline Rangpur & $1.35^{*}(0.97-1.87)$ & & & $1.1(0.78-1.56)$ \\
\hline Sylhet & $0.56^{* * *}(0.38-0.83)$ & - & - & $0.55^{* * *}(0.37-0.84)$ \\
\hline \multicolumn{5}{|l|}{ Place of residence } \\
\hline Urban & 1.00 & - & - & 1.00 \\
\hline Rural & $1.40^{* * *}(1.15-1.71)$ & - & - & $0.99(0.77-1.28)$ \\
\hline
\end{tabular}

Note: ${ }^{* * *}$ denotes $p$-value $<0.01,{ }^{* *}$ denotes $p$-value $<0.05,{ }^{*}$ denotes $p$-value $<0.10$

${ }^{1}$ Univariate logistic regression models considered each variable separately

${ }^{2}$ Model 2 considered only individual characteristics

${ }^{3}$ Model 3 considered individual and household characteristics

${ }^{4}$ Model 4 considered individual, household and community characteristics 
Table 4 Socioeconomic inequalities in undiagnosed hypertension in Bangladesh

\begin{tabular}{|c|c|c|c|c|c|c|}
\hline Characteristics & $\begin{array}{l}\text { Poorest (Q1) } \\
(\%)\end{array}$ & $\begin{array}{l}\text { Richest (Q5) } \\
(\%)\end{array}$ & Q1-Q5 & Q1:Q5 & $\begin{array}{l}\text { Concentration } \\
\text { index (C) }\end{array}$ & Standard error (SE) \\
\hline Total & 69.7 & 50.8 & 18.9 & 1.37 & -0.07 & 0.01 \\
\hline \multicolumn{7}{|l|}{ Individual characteristics } \\
\hline \multicolumn{7}{|l|}{ Age in years } \\
\hline $35-49$ & 78.9 & 56.6 & 22.3 & 1.39 & -0.07 & 0.02 \\
\hline $50-64$ & 66.7 & 44.6 & 22.1 & 1.49 & -0.10 & 0.02 \\
\hline$>=65$ & 64.7 & 48.3 & 16.4 & 1.34 & -0.06 & 0.02 \\
\hline \multicolumn{7}{|l|}{ Sex } \\
\hline Male & 83.6 & 57.0 & 26.7 & 1.47 & -0.08 & 0.02 \\
\hline Female & 62.6 & 46.3 & 16.3 & 1.35 & -0.07 & 0.02 \\
\hline \multicolumn{7}{|l|}{ Education } \\
\hline No education & 68.6 & 54.2 & 14.4 & 1.27 & -0.05 & 0.02 \\
\hline Primary & 75.7 & 46.6 & 29.0 & 1.62 & -0.08 & 0.02 \\
\hline Secondary & 77.3 & 52.5 & 24.8 & 1.47 & -0.06 & 0.03 \\
\hline Higher & 0.0 & 48.2 & -48.2 & 0.00 & -0.03 & 0.04 \\
\hline \multicolumn{7}{|l|}{ Marital status } \\
\hline Currently married & 72.4 & 52.4 & 20.0 & 1.38 & -0.07 & 0.01 \\
\hline Divorced/separated/others & 64.0 & 44.6 & 19.4 & 1.44 & -0.07 & 0.02 \\
\hline \multicolumn{7}{|l|}{ Body weight } \\
\hline Normal & 76.6 & 57.1 & 19.5 & 1.34 & -0.06 & 0.01 \\
\hline Underweight & 66.7 & 60.9 & 5.8 & 1.10 & -0.03 & 0.02 \\
\hline Overweight/obese & 36.6 & 39.6 & -3.1 & 0.92 & -0.07 & 0.03 \\
\hline \multicolumn{7}{|l|}{ Household characteristics } \\
\hline \multicolumn{7}{|l|}{$\mathrm{HH}$ having child } \\
\hline No child & 69.6 & 49.5 & 20.2 & 1.41 & -0.08 & 0.01 \\
\hline Has child & 69.9 & 53.1 & 16.8 & 1.32 & -0.05 & 0.02 \\
\hline \multicolumn{7}{|l|}{ Community characteristics } \\
\hline \multicolumn{7}{|l|}{ Division } \\
\hline Barisal & 67.8 & 38.1 & 29.7 & 1.78 & -0.09 & 0.04 \\
\hline Chittagong & 59.3 & 39.4 & 19.9 & 1.51 & -0.12 & 0.04 \\
\hline Dhaka & 63.4 & 55.7 & 7.7 & 1.14 & -0.04 & 0.03 \\
\hline Khulna & 70.1 & 52.1 & 18.0 & 1.35 & -0.07 & 0.02 \\
\hline Rajshahi & 83.7 & 48.1 & 35.6 & 1.74 & -0.04 & 0.03 \\
\hline Rangpur & 77.3 & 58.4 & 18.9 & 1.32 & -0.07 & 0.02 \\
\hline Sylhet & 65.4 & 34.9 & 30.6 & 1.88 & -0.17 & 0.05 \\
\hline \multicolumn{7}{|l|}{ Place of residence } \\
\hline Urban & 74.7 & 52.6 & 22.1 & 1.42 & -0.04 & 0.02 \\
\hline Rural & 69.3 & 47.6 & 21.8 & 1.46 & -0.08 & 0.01 \\
\hline
\end{tabular}

of $C=0.05)$ and lower in Dhaka $(C=-0.04$, SE of $C=0.03)$ and Rajshahi $(\mathrm{C}=-0.04$, SE of $\mathrm{C}=0.03)$ division.

\section{Discussion}

This study investigated the prevalence of undiagnosed hypertension among Bangladeshi adults and associated socioeconomic inequalities. It was observed that $59.9 \%$ remained hypertensive during the survey and was not diagnosed before. This could be due to lack of awareness, inaccessibility to screening services and the patient's unwillingness to go to doctors for a regular check-up until any or related health complication arises [23]. Undiagnosed hypertension is highly prevalent in Bangladesh. Different estimates of undiagnosed 
hypertension were found in the literature. Islam et al. 2016 showed that among the hypertensive patients, the prevalence was $82 \%$ in the rural area [13]. Conversely, a much lower rate of undiagnosed hypertension was noticed by Khanam et al. 2012 in rural Bangladesh [9]. The variations could likely be due to the smaller sample domain, covering only rural participants from one to three sub-districts, differences in the age group of the selected participants. However, we selected participants aged 35+ years where Khanam et al. 2012 selected 30+ years for estimating the prevalence of undiagnosed hypertension [9].

We found the prevalence of undiagnosed hypertension was lower in higher educated participants compared to the lower educated participants. The possible reason could be the educated people are more aware of hypertension and have better health-seeking behaviour and also have relatively more affordability and accessibility to medical services compared to the lower educated participants [24].

In addition, this study revealed that the prevalence of undiagnosed hypertension was higher among people from the low socioeconomic status which was similar to the findings of undiagnosed hypertension in a rural district in Bangladesh [13]. The poor people have lower access to healthcare facilities in Bangladesh which may lead to have few chances to diagnose their hypertension [25]. Moreover, it is expensive for poor people to get a hypertension screening test that includes transportation time to a medical facility, long waiting time, and the monetary costs [23]. Therefore, the level of education and wealth are two of the most important socioeconomic factors for undiagnosed hypertension.

Older and female patients were likely to have lower risks of being undiagnosed for hypertension. Studies showed that in South Asian countries, the risk of cardiovascular diseases began at the age of 40 years and immunity steadily goes down with the increase in age $[26,27]$. As a result, people face frequent health disorders and have to visit physicians. Nonetheless, this creates an opportunity to get diagnosed with some typical health screening, including hypertension. According to the BDHS (2011), awareness regarding hypertension was higher among the females compared to the males which undeniably leads to lower risk of being undiagnosed for hypertension [14].

It is, however, important to note that overweight individuals had a lower prevalence of undiagnosed hypertension compared to normal BMI. An obese individual possesses a higher risk of developing hypertension [28]. Hence, the chance of diagnosing hypertension is high in this group due to the higher number of physicians visits for health screening related to other chronic condition (e.g. unfavourable cardiovascular outcome, diabetes) $[9,13,29]$.
The prevalence of undiagnosed hypertension varied in different health systems. Unlike high-income countries, undiagnosed hypertension is high in LMICs like Bangladesh. For example, the prevalence of undiagnosed hypertension was $18 \%$ in the USA and $17 \%$ in China $[15,24]$. This is because high-income countries (e.g. USA, Australia, China, and Canada) have more functional health centres and private clinics that outfit for the needs of the citizen. Such facilities do not widely exist in LMICs [24, 30, 31].

In this study, place of residence (e.g. urban and rural residence) was not significantly associated with undiagnosed hypertension. The number of healthcare facilities (including private facilities) is higher in the urban area in comparison to the rural area [32]. However, population rate is also commensurate in the urban area compared to the rural area [33]. Moreover, access to healthcare facilities do not necessarily turn to the deployment of such facilities to expedite detection and diagnosis unless the facilities ensure proper diagnostic services for hypertension. Khanam et al. 2014 showed that qualified providers (e.g. M.B.B.S, specialized doctors) diagnosed only $53.5 \%$ and among unqualified providers, $40.7 \%$ diagnosed by the informal healthcare provider (e.g. quack, village doctors) [34]. The 2014 Bangladesh Health Facility Report suggested that the diagnostic capacity for screening tests of NCDs was low in primary level healthcare facilities of Bangladesh [35]. According to the action plan for NCDs under Health Population and Nutrition Sector Program (HPNSP), primary health care facilities can be reoriented to provide basic screening services for NCDs including hypertension [36]. However, a large number of primary level healthcare provider needs to be trained before implementing such an intervention.

BDHS 2011 reported that $66.0 \%$ of the hypertensive patients are currently taking medicine to lower the high blood pressure [14] which indicates another challenge to the health systems of Bangladesh to ensure treatment of the hypertensive patient. A recently conducted study on costing of essential service package found that on an average the cost per hypertensive patient for drugs, supplies, and human resources was 4500.5 BDT (57.5 USD) for 1 year period in primary and secondary level facilities of Bangladesh [37].

In several studies, it was evident that poor people face financial hardship while accessing healthcare in Bangladesh [38-40] due to high reliance on out-ofpocket healthcare payment. For example, Khan et al. 2017 found that the poor household faced a higher incidence of catastrophic health expenditure compared to other wealth groups [39]. In another study in rural Rajshahi, it was observed that poor economic status was one of the determinants of financial catastrophe for chronic illness [40]. Currently, healthcare services are 
limited at the primary level public healthcare facilities. People usually pay the high out-of-pocket payment for seeking treatment for hypertension from private healthcare facilities in Bangladesh (Masuma Akter Khanam et al., 2014; Rahman, Gilmour, Saito, Sultana, \& Shibuya, 2013).

We found that residents of the Sylhet region were at lower risk of undiagnosed hypertension compared to the Khulna region. A study showed that participants from the Sylhet region were less likely to have hypertension (16.0\%) compared to other regions in Bangladesh [41]. The lower prevalence of hypertension may result in a lower prevalence of undiagnosed hypertension in Sylhet region. However, this needs further examination for identifying the contextual factor of undiagnosed hypertension in Sylhet region. Currently, a limited number of studies are available on the geographical distribution of prevalence of hypertension and its risk factors in Bangladesh.

The Government of Bangladesh has documented several policies in its last Non-Communicable Disease Control Operational Plan (2017-2022). Under the Operational Plan, Primary Health Care system (Community, Community Clinic, Union Health Facility, and Upazila Health Complex) will be used for prevention of NCDs through public awareness, screening and early detection, treatment and referral. Action will be taken to develop the existing hypertension management guideline, train of doctors and non-doctors for hypertension management, smooth the supply of essential medicines and technologies, supply of subsidized treatment for poor, raise public and political awareness/understanding about NCDs and their risk factors through social marketing, mass media and responsible media reporting, and promote healthy lifestyle and practices at community level and at facility levels $[42,43]$. However, there is a lack in implementing the undertaken policies in the past years [44]. In 2013, the Ministry of Health and Family Welfare has developed a guideline for detecting and treating the hypertension in Bangladesh [44]. The guideline recommended lifestyle modification and physical activity as a non-pharmaceutical treatment in early stage (stage 1) of hypertension.

The blood pressure of individuals was measured three times with 10 minutes interval between each measurement on the day of the survey rather than monitoring for a prolonged period which was a potential limitation of this study. However, multiple visits to a household for a prolonged period were not feasible for such a huge sample size. The potential risk factors identified as having the associations with undiagnosed hypertension were not causal due to the cross-sectional nature of the data. However, as the larger sample allows getting precise estimates and adjustment of confounders, we had the opportunity to find the association between the prevalence of undiagnosed hypertension and the socioeconomic factors.

\section{Conclusion}

This study showed that a large proportion of the cases with hypertension remained undiagnosed in Bangladesh especially among the poor and the low education group. Awareness about high blood pressure is required at an individual level to check and follow-up blood pressure level routinely. Policies to prevent hypertension has already been developed in the strategic plan and operational plan, however, implementing the undertaken policies is the key issue. The primary healthcare facilities need to be strengthened by making drugs and screening facilities available for preventing hypertension. As the undiagnosed hypertension is remarkably higher besides the burden of hypertension is rising, policy focus needs to be reinforced to ensure fruitful application of it. Although publicly financed insurance and health vouchers have been proposed in the strategic investment plan to protect the poor against the cost of care for chronic diseases and catastrophic illnesses, efforts towards prevention and control of hypertension should be prioritized and planned actions under the operational plan should be properly implemented. Further, the surveillance system needs to be conducted to track the rising burden of hypertension as well as to detect the undiagnosed cases and to intervene accordingly at the community level.

\section{Abbreviations}

AHA: American Heart Association; AOR: Adjusted odds ratios; BDHS: Bangladesh Demographic and Health Survey; BMI: Body-mass index; C: Concentration index; Cl: 95\% confidence intervals; DBP: Diastolic blood pressure; LMICs: Low and middle-income countries; NCDs: Non-

communicable chronic diseases; OR: Odds ratios; PCA: Principal component analysis; SBP: Systolic blood pressure; SE: Standard error

\section{Acknowledgements}

The authors would like to thank the authority of Bangladesh Demographic and Health Survey 2011 for the dataset. icddr,b is also thankful to the Governments of Bangladesh, Canada, Sweden and the UK for providing core/unrestricted support.

\section{Funding}

The authors did not receive any funding for conducting this study.

\section{Availability of data and materials}

Data was collected from DHS program 2011 and openly accessible after prior permission from DHS authority at https://dhsprogram.com/data/ dataset/Bangladesh_Standard-DHS_2011.cfm?flag=0.

\section{Authors' contribution}

SA and MMH conceptualized the research. SA, MT, MAR, and MMH conducted analysis and prepare the manuscript. SA, MZH, and MMH reviewed and revised the manuscript. All authors read and approved the final manuscript.

\section{Ethics approval and consent to participate}

The study was conducted based on secondary data from Bangladesh Demographic and Health Survey 2011. Thus, we did not require ethics approval for this study. 


\section{Competing interests}

The authors declare that they have no competing interests.

\section{Publisher's Note}

Springer Nature remains neutral with regard to jurisdictional claims in published maps and institutional affiliations.

\section{Author details}

'International Centre for Diarrhoeal Disease Research, Bangladesh (icddr,b), Dhaka 1212, Bangladesh. ${ }^{2}$ Department of Learning, Informatics, Management and Ethics, Karolinska Institutet, Stockholm 171 77, Sweden. ${ }^{3}$ Department of Tropical Disease Biology, Liverpool School of Tropical Medicine (LSTM), Liverpool L3 5QA, UK. ${ }^{4}$ Department of Economics, Faculty of Business and Economics, Macquarie University, Sydney, NSW 2109, Australia. ${ }^{5}$ Institute for Social Science Research, The University of Queensland, Indooroopilly 4068 Queensland, Australia.

Received: 28 July 2018 Accepted: 28 January 2019 Published online: 15 February 2019

\section{References}

1. Petrela E, Burazeri G, Pupuleku F, Zaimi E, Rahman M. Prevalence and correlates of hypertension in a transitional southeastern European population: results from the Albanian Demographic and health Survey. Arh Hig Rada Toksikol Croatia. 2013;64:479-87.

2. Chockalingam A, Campbell NR, George FJ. Worldwide epidemic of hypertension. Can J Cardiol Elsevier. 2006;22:553-5.

3. WHO. A global brief on hypertension. In: Geneva; 2013.

4. Anand Krishnan RG, AK P. Hypertension in the South-East Asia region: an overview. Reg heal forum. New-Delhi. 2013;17:90

5. Hypertension Study Group. Prevalence, awareness, treatment and control of hypertension among the elderly in Bangladesh and India: a multicentre study. Bull World Heal Organ. 2001;79:490-500.

6. Lozano R, Naghavi M, Foreman K, Lim S, Shibuya K, Aboyans V, et al. Global and regional mortality from 235 causes of death for 20 age groups in 1990 and 2010: a systematic analysis for the global burden of disease study 2010. Lancet (London, England). 2012;380:2095-128.

7. Reubi D, Herrick C, Brown T. The politics of non-communicable diseases in the global south. Heal Place. 2016;39:179-87.

8. WHO. World health Day: high blood pressure global and regional overview. In: Geneva; 2013

9. Khanam MA, Lindeboom W, Razzaque A, Niessen L, Smith W, Milton AH. Undiagnosed and uncontrolled hypertension among the adults in rural Bangladesh. J Hypertens. 2015;33:2399-406.

10. DGHS. Health bulletin 2016. Dhaka; 2016

11. Monwarul Islam AKM, Majumder AAS. Hypertension in Bangladesh: A review. Indian Heart J. Cardiological Society of India; 2012;64:319-23.

12. Chowdhury MAB, Uddin MJ, Haque MR, Ibrahimou B. Hypertension among adults in Bangladesh: evidence from a national cross-sectional survey. BMC Cardiovasc Disord. BioMed Central. 2016;16:22.

13. Islam FMA, Bhuiyan A, Chakrabarti R, Rahman MA, Kanagasingam Y, Hiller JE Undiagnosed hypertension in a rural district in Bangladesh: The Bangladesh Population-based Diabetes and Eye Study (BPDES). J Hum Hypertens. Nature Publishing Group; 2016;30:252-9.

14. National Institute of Population Research and Training (NIPORT), Mitra and Associates, and ICF International. Bangladesh Demographic and Health Survey 2011. Dhaka, Bangladesh and Calverton, Maryland, U SA; 2013

15. Xiaohui Hou X. Urban-Rural Disparity of Overweight, Hypertension, Undiagnosed Hypertension, and Untreated Hypertension in China. Asia Pacific J Public Heal. Sage PublicationsSage CA: Los Angeles, CA. 2008;20: 159-69.

16. Vyas S, Kumaranayake L. Constructing socio-economic status indices: how to use principal components analysis. Health Policy Plan. 2006;21:459-68.

17. Filmer D, Pritchett LH. Estimating wealth effects without expenditure Data or tears. Demography. 2001;38:115-32.

18. Wagstaff A, Doorslaer E, van Paci P. On the measurement of horizonta inequity in the delivery of health care. J Health Econ. 1991:10:169-205.

19. Kakwani N, Wagstaff A, van Doorslaer E. Socioeconomic inequalities in health: measurement, computation, and statistical inference. J Econom. 1997;77:87-103
20. O'Donnell O, Van Doorslaer E, Wagstaff A, Lindelow M. Analyzing health equity using household survey data: a guide to techniques and their implementation. Washington D.C: The World Bank; 2007.

21. Koolman $X$, Doorslaer $E$ van. On the interpretation of a concentration index of inequality. Health Econ. 2004;13:649-56.

22. StataCorp. Stata Statistical Software: Release 13. College Station, TX: StataCorp LP.; 2013.

23. Uddin MJ, Alam N, Sarma H, Chowdhury MA, Alam DS, Niessen L. Consequences of hypertension and chronic obstructive pulmonary disease, healthcare-seeking behaviors of patients, and responses of the health system: a population-based cross-sectional study in Bangladesh. BMC Public Health. 2014;14:547.

24. Zoellner J, Thomson JL, Landry AS, Anderson-Lewis C, Connell C, Molaison $E F$, et al. Improvements in blood pressure among undiagnosed hypertensive participants in a community-based lifestyle intervention, Mississippi, 2010. Prev Chronic Dis. 2014;11:130269.

25. Khan JAM, Ahmed S, Maclennan M, Sarker AR, Sultana M, Rahman H. Benefit incidence analysis of healthcare in Bangladesh - equity matters for universal health coverage. Health Policy Plan. 2016;0:1-7.

26. Gupta R, Misra A, Vikram NK, Kondal D, Gupta S Sen, Agrawal A, et al. Younger age of escalation of cardiovascular risk factors in Asian Indian subjects. BMC Cardiovasc Disord. BioMed Central; 2009;9:28.

27. Joshi P, Islam S, Pais P, Reddy S, Dorairaj P, Kazmi K, et al. Risk factors for early myocardial infarction in south Asians compared with individuals in other countries. JAMA. American Medical Association. 2007;297:286.

28. Julius S, Valentini M, Palatini P. Overweight and hypertension: a 2-way street? Hypertension. 2000;35:807-13.

29. Whitlock EP, O'Conner EA, Williams SB, Beil TL, Lutz KW. Effectiveness of primary care interventions for weight Management in Children and Adolescents. Eff. Prim. Care Interv. Weight Manag. Child. Adolesc. An Updat. Target. Syst. Rev. USPSTF. Agency for Healthcare Research and Quality: US; 2010

30. Janus ED, Bunker SJ, Kilkkinen A, Namara KM, Philpot B, Tideman P, et al. Prevalence, detection and drug treatment of hypertension in a rural Australian population: the greater green triangle risk factor study 2004-2006. Intern Med J. 2008:38:879-86.

31. Briganti EM, Shaw JE, Chadban SJ, Zimmet PZ, Welborn TA, JJ MN, Atkins RC. Untreated hypertension among Australian adults: the 1999-2000 Australian Diabetes, Obesity and Lifestyle Study (AusDiab). Med J Aust. 2003; 179(3):135-9.

32. icddr b. Assessment of Maternal, Neonatal, Child Health and Family Planning Facilities in Bangladesh. Dhaka; 2012

33. BBS. Population and housing census 2011. In: Dhaka; 2011.

34. Khanam MA, Lindeboom W, Koehlmoos TL, Alam DS, Niessen L, Milton AH. Hypertension: adherence to treatment in rural Bangladesh - findings from a population-based study. Glob Heal Action. 2014;7:25028.

35. NIPORT. Bangladesh health facility Survey 2014. Dhaka; 2014.

36. MoHFW. Multisectoral action Plan for the noncommunicable disease contro and prevention (2016-2021) with a three year Operational Plan government of Bangladesh. In: Dhaka; 2016

37. Islam Z, Ahmed S, Dorin FA, Hasan MZ, Ahmed MW, Mahmood SS, et al. Costs of the Bangladesh essential health service package: 2016- 2022 Ministry of Health and Family Welfare, Government of the People's Republic of Bangladesh. Dhaka; 2018.

38. van Doorslaer E, O'Donnell O, Rannan-Eliya RP, Somanathan A, Adhikari SR, Garg CC, et al. Effect of payments for health care on poverty estimates in 11 countries in Asia: an analysis of household survey data. Lancet. 2006:368: 1357-64.

39. Khan J, Ahmed S, Evans T. Catastrophic healthcare expenditure and poverty related to out-of-pocket payments for healthcare in Bangladesh - an estimation of financial risk protection of universal health coverage. Health Policy Plan. 2017:1-9.

40. Rahman MM, Gilmour S, Saito E, Sultana P, Shibuya K. Health-related financial catastrophe, inequality and chronic illness in Bangladesh. PLoS One. 2013;8:e56873.

41. Hoque ME, Khokan MR, Bari W. Impact of Stature on Non-communicable Diseases : Evidence Based on BDHS, 2011 Data. BMC Public Health. 2014;14:1-8.

42. MOHFW. Operational Plan (2017-22): non communicable disease control. Ministry of Health and Family Welfare, Government of the People's Republic of Bangladesh.Dhaka; 2017. 
43. MOHFW. Expanding Social Protection for Health: Towards universal coverage, health care financing strategy 2012-2032.Ministry of Health and Family Welfare, Government of the People's Republic of Bangladesh. Dhaka; 2012.

44. DGHS. National Guidelines for Management of Hypertension in Bangladesh. Ministry of Health and Family Welfare, Government of the People's Republic of Bangladesh. Dhaka; 2013.

Ready to submit your research? Choose BMC and benefit from:

- fast, convenient online submission

- thorough peer review by experienced researchers in your field

- rapid publication on acceptance

- support for research data, including large and complex data types

- gold Open Access which fosters wider collaboration and increased citations

- maximum visibility for your research: over $100 \mathrm{M}$ website views per year

At $\mathrm{BMC}$, research is always in progress.

Learn more biomedcentral.com/submissions 